\title{
Analysis and pressure material selection for vessels that complies with the safety conditions of service within a hidrotatamento unit (hdt) in a refinery.
}

\author{
Aline Raquel Vieira Nunes'; Ana Emília Diniz Silva Guedes²; Daniel Lago Mousinho²; Antônio Adalberto Cavalcante \\ Moreira Filho²; Silvio Batista Soares Neto $^{2}$; Tirso Lorenzo Rayes Carvajal ${ }^{3}$ \\ ${ }^{1}$ Federal University of Rio de Janeiro, Rio de Janeiro/RJ- Brazil (alinemateriais@ hotmail.com) \\ ${ }^{2}$ Federal University of Rio Grande do Norte, Natal/RN - Brazil (aedsguedes@ gmail.com; danielm.lago@ yahoo.com.br; \\ adalbertocmoreira@gmail.com; silvios.eng@gmail.com) \\ ${ }^{3}$ Instituto de Tecnologia e Educação Galileo da Amazônia (ITEGAM) - Manaus/AM-Brasil (tirsolrca@gmail.com)
}

\begin{abstract}
Oil refineries are one of the industries most important to the functioning of the country that generate end products from oil received from production fields. The different locations in the refinery where occur the refining processes are the process units, also called refining or processing units. Each of these units comprises a set of equipment responsible for a refining step. The hydrotreating catalyst is a hydrogenation process which is currently operated at the refineries with a performance degradation of about $90 \%$ of compounds of sulfur, nitrogen and oxygen from the liquid fractions of petroleum distillates. Refinery pressure vessels are not only the most important features of most process industries, as well as usually the larger items, weight and unit costs, representing on average $60 \%$ of the total cost of materials and unit equipment process. This paper aims to describe the procedures for correct analysis and selection of materials to be used in pressure vessels, which meets with security service conditions within a unit at the refinery, taking into account the mechanical properties of materials, corrosion resistance, welding, obtaining facilities manufacturing and the expected useful life, based on the ASME code, the PETROBRAS and ASTM standards.
\end{abstract}

Keywords: Oil refineries, pressure vessels, selection of materials, mechanical properties

\section{Análise e seleção de materiais para vasos de pressão que atenda com segurança as condições de serviço dentro de uma unidade de hidrotatamento (HDT) em uma refinaria.}

\section{RESUMO}

As refinarias de petróleo, são uma das industrias de maior importância para o funcionamento do pais que geram os produtos finais a partir do petróleo recebido dos campos de produção. Os diferentes locais na refinaria onde ocorrem os processos de refino são as Unidades de Processo, também chamadas Unidades de Refino ou de Processamento. Cada uma dessas Unidades é composta por um conjunto de equipamentos responsável por uma etapa do refino. O hidrotratamento catalítico é um processo de hidrogenação que atualmente tem operado nas refinarias com um rendimento de degradação de cerca de $90 \%$ dos compostos de enxofre, nitrogênio e oxigênio das frações líquidas dos destilados petrolíferos. Nas refinarias os vasos de pressão constituem não só os equipamentos mais importantes da maioria das indústrias de processo, como também são geralmente os itens de maior tamanho, peso e custo unitário, representando em média $60 \%$ do custo total dos materiais e equipamentos de uma unidade de processo. Este trabalho tem como objetivo descrever os procedimentos para uma correta análise e seleção de materiais a serem utilizados em vasos de pressão, que atenda com segurança as condições de serviço dentro de uma Unidade na refinaria, levando-se em consideração as propriedades mecânicas dos materiais, resistência a corrosão, soldagem, facilidades de obtenção de fabricação e à vida útil esperada, baseados no código ASME, nas normas PETROBRAS e ASTM.

Palavras Chaves: Refinarias de petróleo, vasos de pressão, seleção de materiais, propriedades mecânicas.

\section{INTRODUÇÃO}

Numa indústria petrolífera, são as refinarias que geram os produtos finais a partir do petróleo recebido dos campos de produção [1].
Depois de extraído e tratado no campo de produção, o petróleo segue para a refinaria, para ser transformado na série de derivados que vão atender as necessidades de algum mercado. Nem todos os derivados são gerados de uma só vez e em um mesmo local na refinaria. Quase sempre, eles são obtidos após uma sequencia de processos, chamados de operações unitárias e

ITEGAM - JETIA Vol. 02, Nº.07. Setembro de 2016. Manaus - Amazonas, Brasil. ISSN 2447-0228 (ONLINE). 
Aline R. V. Nunes, et al. / ITEGAM-JETIA Vol.02, Nº 07, pp.04-16. Setembro, 2016.

que consiste em transformações de um ou mais fluidos (gás e/ou líquido), que servem de entradas do processo, em outros fluidos, chamados saídas do processo [1].

Os diferentes locais na refinaria onde ocorrem os processos de refino são as Unidades de Processo, também chamadas Unidades de Refino ou de Processamento.

Cada uma dessas Unidades é composta por um conjunto de equipamentos responsável por uma etapa do refino. Alguns derivados já são produzidos na saída da primeira unidade de processamento, enquanto outros aparecem somente após a passagem por várias unidades de processo.

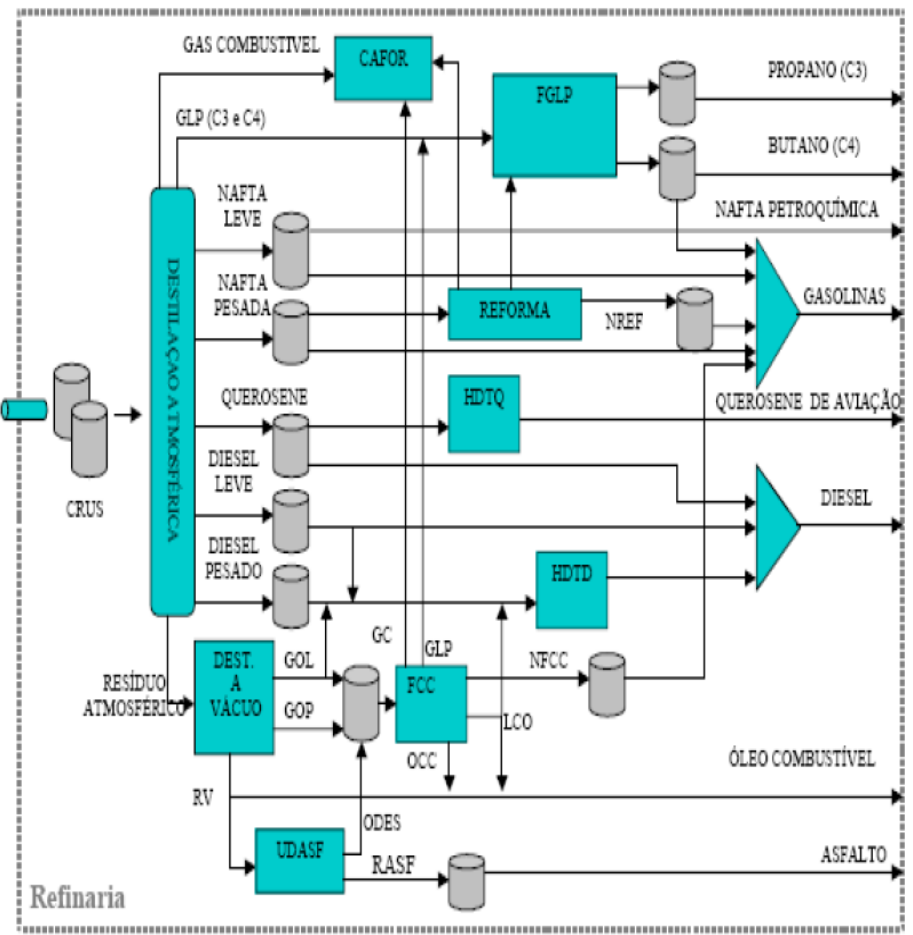

Figura 1- Esquema geral de uma Refinaria.

Fonte: [1].

O hidrotratamento catalítico (que opera na unidade de hidrotratamento (HDT)) é um processo de hidrogenação que atualmente tem operado nas refinarias com um rendimento de degradação de cerca de $90 \%$ dos compostos de enxofre, nitrogênio e oxigênio das frações líquidas dos destilados petrolíferos [2][3].

Para suportar altos níveis de pressão, temperatura e corrosividade a custos de construção não proibitivos, alguns equipamentos utilizados nas unidades de hidrotratamento são fabricados em materiais bimetálicos, isto é, compõem-se de uma espessa camada de metal base e uma camada mais fina de revestimento metálico, que tem por objetivo a combinação de resistência mecânica, resistência à corrosão e custo. Como revestimento, os aços inoxidáveis austeníticos podem ser utilizados para garantir resistência à corrosão por misturas $\mathrm{H}_{2} / \mathrm{H}_{2} \mathrm{~S}$ e ao ataque ao hidrogênio em alta temperatura [4].
Os vasos de pressão constituem não só os equipamentos mais importantes da maioria das indústrias de processo, como também são geralmente os itens de maior tamanho, peso e custo unitário, representando em média $60 \%$ do custo total dos materiais e equipamentos de uma unidade de processo. O projeto e a construção de vasos de pressão envolvem uma série de cuidados especiais e exige o conhecimento de normas e materiais adequados para cada tipo de aplicação, pois as falhas em vasos de pressão podem acarretar consequências catastróficas até mesmo com perda de vidas, sendo considerados equipamentos de grande periculosidade [5].

Este trabalho tem como objetivo descrever os procedimentos para uma correta análise e seleção de materiais a serem utilizados em vasos de pressão, que atenda com segurança as condições de serviço dentro de uma Unidade de HDT na refinaria, levando-se em consideração as propriedades mecânicas dos materiais, resistência a corrosão, soldagem, facilidades de obtenção de fabricação e à vida útil esperada, baseados no código ASME, nas normas PETROBRAS e ASTM.

\section{UNIDADES DE REFINO DE PETRÓLEO}

O petróleo não é uma substância pura, mas uma mistura de compostos orgânicos e inorgânicos onde predominam os hidrocarbonetos, que, por si só, tem pouquíssimas aplicações práticas, servindo quase que tão somente como óleo combustível.

O refino de petróleo constitui a separação deste insumo, via processos físico-químicos, em frações de derivados, que são processados em unidades de separação e conversão até os produtos finais. Os produtos finais dividem-se em 3 categorias [6]

- Combustíveis (gasolina, diesel, óleo combustível, GLP, QAV, querosene, coque de petróleo, óleos residuais) - cerca de $90 \%$ dos produtos de refino do mundo;

- Produtos acabados não combustíveis (solventes, lubrificantes, graxas, asfalto e coque), e;

- Intermediários da indústria química (nafta, propano, butano, etileno, propileno, butilenos, BTX).

Atualmente, é intensa a pesquisa pela melhoria dos processos de refino disponíveis, visando principalmente superar os desafios oferecidos pelo processamento de óleos não convencionais, como o petróleo do tipo Marlim [2].

Os processos de refino existentes costumam ser divididos em quatro grandes grupos:

- Processos de separação;

- Processos de conversão;

- Processos de tratamento;

- Processos auxiliares.

$\mathrm{O}$ encadeamento das várias unidades de processo dentro de uma refinaria é o que se denomina de "Esquema de Refino". A Figura 2 apresenta o esquema do processo de refino. 


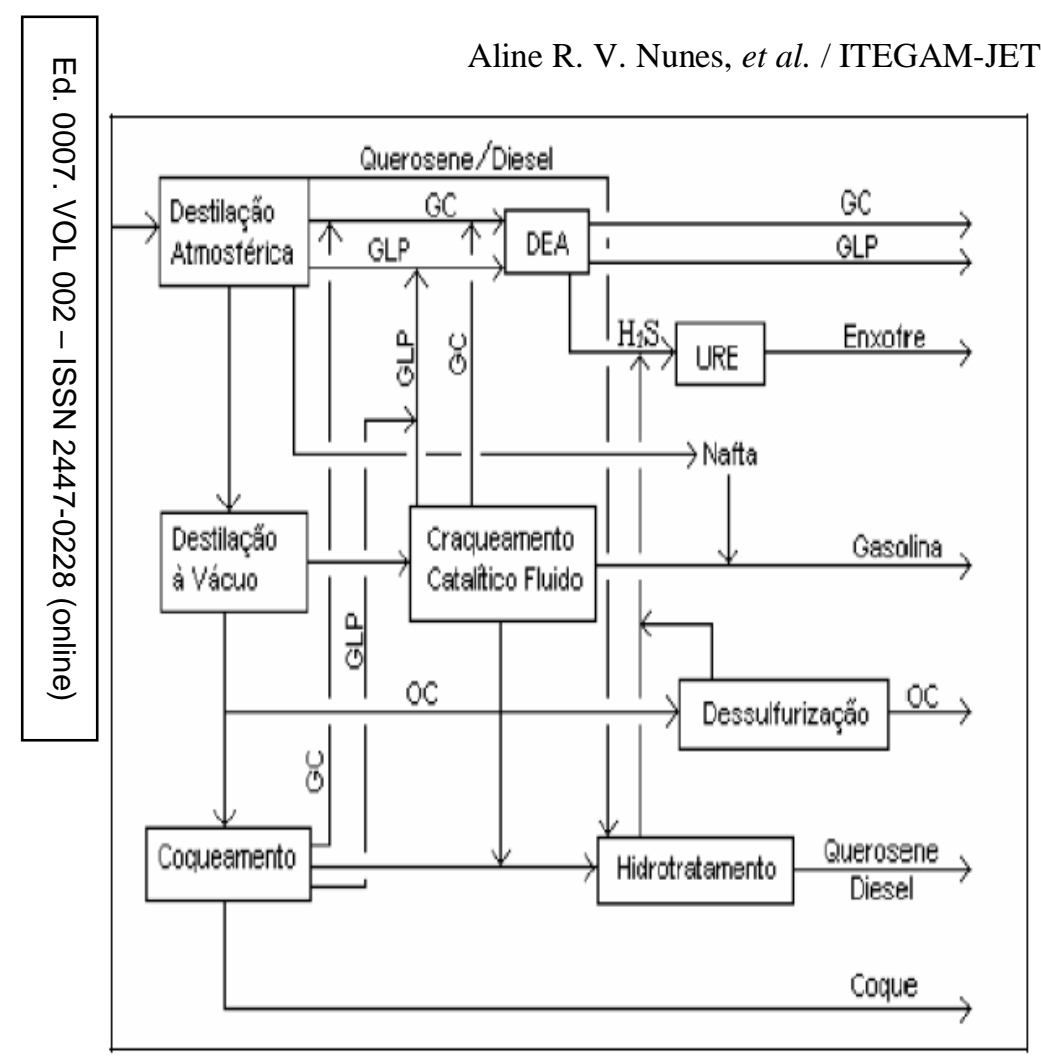

Figura 2 - Esquema de Refino.

Fonte: [2].

\section{II.1. PROCESSOS CONSUMIDORES DE HIDROGÊNIO}

Basicamente, dois são os tipos de processo que podem ser incluídos nos consumidores de hidrogênio: hidrocraqueamento e hidrotratamento (que faz parte do processo de tratamento). Ambos usam catalisador metálico e atmosfera redutora [6][7].

O hidrotratamento é um processo que consiste na remoção de impurezas como compostos sulfurados, oxigenados (ácidos naftênicos, por exemplo), nitrogenados, organo-metálicos, e na hidrogenação de insaturados (nitrogênio, oxigênio, halogênios e metais). É considerado um processo estratégico para o aproveitamento de cargas residuais e de óleos pesados. Trata-se de uma reação com hidrogênio que ocorre em ambiente de alta pressão, na presença de um catalisador que comumente contêm óxidos de cobalto e de molibdênio, em suporte de alumina. $\mathrm{O}$ Hidrotratamento ainda aumenta a qualidade de frações, convertendo olefinas e diolefinas em parafinas, o que reduz a formação de gomas nos combustíveis[6][7][8].

A maioria dos esquemas de HDT emprega um reator de um ou mais estágios, com leito fixo de catalisador, operando sob alta pressão e com a condição de hidrogênio. Este hidrogênio é provido por unidades da própria refinaria, como a unidade de reforma catalítica, ou por unidade especificas de produção de hidrogênio. Os produtos básicos do HDT são: gases de hidrocarbonetos leves, ácido sulfídrico, amônia e carga tratada[6][7]

O hidrotratamento consiste num importante grupo de processos na indústria do refino do petróleo e que tem sido usado amplamente ao longo de 40 anos. Os primeiros processos que surgiram foram os de hidropurificação, os quais consistiam basicamente em remover heteroátomos como enxofre $(\mathrm{S})$, nitrogênio $(\mathrm{N})$, oxigênio $(\mathrm{O})$, vanádio $(\mathrm{V})$, níquel $(\mathrm{Ni})$, entre outros, de moléculas orgânicas. Podemos classificar esses processos como[2]:

○ Remoção de enxofre: hidrodessulfurização (HDS): degradação em ácido sulfídrico e um hidrocarboneto

- Remoção de nitrogênio: hidrodenitrogenação (HDN): degradação em amônia e um hidrocarboneto.

○ Remoção de oxigênio: hidrodeoxigenação (HDO): degradação em água e um hidrocarboneto.

Especificações mais rigorosas para o teor de enxofre dos combustíveis fazem com que as refinarias invistam em unidade de hidrossulfurização severa ou busquem processos alternativos para a dessulfuriração.

\section{2 VASOS DE PRESSÃO}

Vasos de Pressão são todos os reservatórios, de qualquer tipo, dimensões ou finalidades, não sujeitos à chama, fundamentais nos processos industriais, que contenham fluídos e sejam projetados para resistir com segurança a pressões internas superiores a $100 \mathrm{kPa}$ ou inferiores à pressão atmosférica, ou submetidos à pressão externa, cumprindo assim a função básica de armazenamento.

Os vasos de pressão têm como finalidade separar vaporlíquido, separar vapor-líquido-líquido, separar líquido-líquido, prover tempo de resistência ao processo, prover tempo de estocagem de carga, fazer misturas, reações químicas e etc.

\section{II.2.1 FORMATO DOS VASOS DE PRESSÃO}

O corpo dos vasos de pressão é formado basicamente pelos seguintes itens:

- Casco (shell): são construídos de chapas calandradas e soldadas ou de tubos comerciais. Em geral, possuem formato cilíndrico devido a maior facilidade de fabricação. Quando constituídos com seções transversais de diâmetros diferentes usa-se transições cônicas.

- Tampos (heads): são as peças de fechamento dos cascos cilíndricos dos vasos de pressão. Podem ser encontrados nos seguintes formatos: elípticos, torisféricos, hemisféricos, planos, cônicos e calotas esféricas.

\section{II.2.2 FLANGES}

Flanges são utilizados quando se deseja criar uma conexão não permanente com o equipamento. Em geral, os flanges são forjados. Para flanges de grandes diâmetros, onde a fabricação forjada é complicada, é aceitável a fabricação a partir de chapas, barras ou aço fundido[5][9].

Flanges são peças padronizadas pelas normas ASME B16.5 e B-16.47 (exceto flanges de anel e de pescoço longo). São classificados em classes de pressão designadas por números adimensionais 150\#, 300\#, 400\#, 600\#, 900\#, 1500\# e 2500\#.

A pressão admissível de um flange padronizado é função do seu material, classe de pressão e da temperatura. 
Aline R. V. Nunes, et al. / ITEGAM-JETIA Vol.02, No 07, pp.04-16. Setembro, 2016.

Existem diversos tipos de flanges para bocais, bocas de visita e de instrumentação.

- Flange de pescoço (weld neck)

- Flange sobreposto (slip-on)

- Flange tipo anel (ring type)

- Flange para solda de encaixe (socket-weld)

- Flange de pescoço longo (long weld neck)

- Flange solto (lap-joint)

- Flange cego (blind)

A face dos flanges também pode ser de vários tipos. Os mais comuns são face de ressalto, face plana e face para junta e anel. A junta utilizada deve ser definida em função do serviço [5].

\section{II.2.3. SUPORTES PARA VASOS DE PRESSÃO}

Todos os vasos de pressão devem possuir suporte próprio. Os suportes mais comuns em vasos verticais são [5][10].

- Saia cilíndrica: possui boa distribuição de tensões. Utilizada em vasos de grandes dimensões.

- Saia cônica: é empregada quando é necessária uma maior estabilidade ou para permitir uma distância adequada entre chumbadores.

- Sapatas: são fabricadas a partir de chapas e utilizadas para vasos de pequenas dimensões.

- Colunas: são fabricadas a partir de perfis ou cantoneiras e utilizada em vasos de pequenas dimensões.

Os vasos horizontais devem ser suportados por meio de duas selas ou berços. Um dos berços deve possuir furos alongados de forma a acomodar a dilatação térmica. Para vasos acima de $20 t$ recomenda-se placas de deslizamento de plástico PTFE no berço móvel. Devem ser situados simetricamente em relação ao meio do comprimento do vaso e distanciados entre si por uma distância de 3/5 do CET [5].

\section{II.2.4. FATORES PARA SELEÇÃO DO MATERIAL PARA VASOS DE PRESSÃO}

A seleção do material adequado a cada uma das partes de um equipamento de processo é, frequentemente, um dos problemas mais difíceis com que se defronta o projetista ou o usuário desses equipamentos. Para cada unidade de processo em projeto, é feita a "especificação de materiais e caracterização de serviços", em que se define os materiais dos componentes de cada vaso de pressão, e os requisitos especiais para projeto e construção, conforme os tipos de serviços em que esses vasos estão envolvidos.

Ao conjunto de fatores presentes em uma determinada condição de operação, associando a agressividade do meio (corrosão), as características metalúrgicas do material (tendência a corrosão sob tensão, ao empolamento, à trincas, à fratura frágil) e os aspectos de toxidez e inflamabilidade do produto, se denomina serviço.

O problema geral consiste em selecionar e especificar um material que atenda com segurança às condições de serviço de uma determinada aplicação, com o menor custo possível, levandose em conta as propriedades mecânicas dos materiais, resistência à corrosão, facilidades de obtenção e fabricação, vida útil, entre outros. A seguir são relacionados os principais fatores que exercem influência na escolha do material para vasos de pressão [2][5][11]:

- Fatores relativos à resistência mecânica do material

- Propriedades mecânicas do material: limite de resistência e escoamento, ductilidade, resistência à fluência e à fadiga, tenacidade, temperatura de transição, dureza e módulo de elasticidade.

- Fatores relativos ao serviço

- Temperatura em que o material deva trabalhar;

- Fluido em contato: composição química, concentração do fluido, corrosividade, ph, impurezas, contaminantes, pressão, temperatura;

- Ação dos fluidos sobre os materiais: fragilização, alterações químicas e metalúrgicas;

- Efeito da corrosão;

- Nível de tensão no material;

- Natureza dos esforços mecânicos;

- Fatores relativos à fabricação do equipamento e montagem;

- Existem alguns fatores que podem dificultar a fabricação, tais como dificuldade de conformação e soldabilidade. Na prática a boa soldabilidade é garantida quando o teor de carbono é, no máximo, $0,26 \%$ e quando o "carbono equivalente" for menor que $0,42 \%$. O carbono equivalente é uma taxa, em função do teor de alguns dos elementos da composição da liga do material, definido como: $\mathrm{CE}$ $=\mathrm{C}+\mathrm{Mn} / 6+(\mathrm{Cr}+\mathrm{Mo}+\mathrm{V}) / 5+(\mathrm{Cu}+\mathrm{Ni}) / 15$. ○

- Disponibilidade dos materiais

- Facilidade de obtenção do material;

- Forma de apresentação do material.

- Custo do material;

- Segurança: evitar a ocorrência de rupturas, vazamentos ou outros acidentes, que possam resultar em paralisações dispendiosas, ou mesmo em desastres;

- Experiência prévia;

- Variações toleradas na forma ou de dimensões da peça.

- Tempo de vida útil.

De acordo com a norma N-253 da Petrobras, devem ser considerados os valores mínimos da Figura 3 para o tempo de vida útil dos vasos de pressão. Esses tempos de vida útil devem ser empregados como base para a seleção de materiais, determinação de sobre-espessuras para corrosão e erosão, cálculo de fadiga e de deformações por fluência, e qualquer outro critério baseado no fator tempo.

Quando for técnica ou economicamente inviável atender a esses tempos de vida, a PETROBRAS deve ser consultada previamente para decidir em cada caso. 
Aline R. V. Nunes, et al. / ITEGAM-JETIA Vol.02, Nº 07, pp.04-16. Setembro, 2016.

\begin{tabular}{|l|c|c|}
\hline \multicolumn{1}{|c|}{ Classes de equipamentos } & $\begin{array}{c}\text { Refinarias, terminais e } \\
\text { outras instalações näo } \\
\text { petroquimicas }\end{array}$ & $\begin{array}{c}\text { Unidades } \\
\text { petroquímicas }\end{array}$ \\
\hline $\begin{array}{l}\text { Equipamentos de grande porte, grande custo ou } \\
\text { essenciais ao funcionamento da unidade } \\
\text { industrial (reatores, torres, trocadores de calor } \\
\text { ou vasos importantes). }\end{array}$ & 20 anos & 15 anos \\
\hline $\begin{array}{l}\text { Outros equipamentos não incluidos na classe } \\
\text { acima. }\end{array}$ & 15 anos & 10 anos \\
\hline $\begin{array}{l}\text { Peças desmontáveis ou de reposição (feixes } \\
\text { tubulares, internos removiveis de torres, e } \\
\text { outros). }\end{array}$ & 8 anos & 5 anos \\
\hline
\end{tabular}

Figura 3 - Vida útil dos vasos de pressão.

Fonte: [11].

\section{II.2.5 PRINCIPAIS TIPOS DE MATERIAIS USADOS EM VASOS DE PRESSÃO}

De todos esses materiais o aço carbono é o de maior uso e empregado na construção da grande maioria dos vasos de pressão, abrangendo uma ampla faixa de temperatura entre $250{ }^{\circ} \mathrm{C}$ e 1100 ${ }^{\circ} \mathrm{C}$. O aço carbono é denominado de "material para uso geral", porque, ao contrário dos outros materiais, não tem casos específicos de emprego, sendo usado em todos os casos, exceto quando alguma circunstância não permitir o seu emprego. Todos os demais materiais são empregados justamente nesses casos em que, por qualquer motivo, não é possível o uso do aço carbono [5].

\section{II.2.5.1 AÇO-CARBONO}

Contém teoricamente, entre 0,05 e $2,0 \%$ de carbono. $\mathrm{Na}$ prática a quantidade nunca é superior a $0,35 \%$. As propriedades do aço carbono são influenciadas por pequenas variações em sua composição química, o aumento na quantidade de carbono provoca um aumento na dureza e nos limites de resistência e escoamento do aço e uma redução na ductilidade, traduzida por uma diminuição no alongamento.

- Material para uso geral;

- $\quad$ Sofrem fluência em temperaturas a partir de $370^{\circ} \mathrm{C}$;

- Não são empregados para temperaturas abaixo de $45^{\circ} \mathrm{C}$

- Apresentam baixa resistência a corrosão

Os aços de baixo carbono são materiais fáceis de trabalhar a frio e de soldar. São empregados principalmente em tubos de pequenos diâmetros (até 4"). O uso de chapas de baixo carbono para vasos de pressão é muito raro. A temperatura limite de uso prático (serviço contínuo) é em torno de $350^{\circ} \mathrm{C}$, e deve ser considerado o efeito de fragilização desses aços para serviços em temperaturas inferiores a $10^{\circ} \mathrm{C}$. Possui em sua composição química até 0,25\% Carbono, 0,90\% Manganês e 0,50\% Silício.

Os aços de médio carbono não são tão fáceis de trabalhar a frio, motivo pelo qual não são empregados para tubos de pequenos diâmetros. Esses aços são muito empregados em vasos de pressão e tubos de grandes diâmetros, preferindo-se sobre os aços de baixo carbono pelo fato de terem melhor resistência mecânica. A temperatura limite de uso prático (serviço contínuo) deve ser $400^{\circ} \mathrm{C}$, deve ser considerado o efeito da fragilidade desses aços para temperaturas inferiores a $15^{\circ} \mathrm{C}$. Possui em sua composição química até $0,35 \%$ carbono e Manganês até $1,20 \%$. Os aços de médio carbono acalmados a temperaturas elevadas seguem as mesmas observações sobre a soldabilidade, limites de carbonos, facilidade de trabalho a frio e temperatura de fragilidade indicadas para os aços de médio carbono não-acalmados. Estes aços, entretanto, são mais caros. São aplicados para temperaturas superiores a $400^{\circ} \mathrm{C}$. Possui em sua composição química até $0,35 \%$ Carbono, Manganês até $1,60 \%$ e Silício até $0,6 \%$.

Os aços de médio carbono acalmados para baixas temperaturas costumam ter uma quantidade de carbono intermediária entre os de baixo e de médio carbono (até aproximadamente $0,23 \%$ ), qualidades mecânicas semelhantes aos aços de médio carbono e quantidade de Mn um pouco mais alta (até 1,6\%), para compensar o decréscimo de carbono. Alguns aços de baixo carbono são acalmados com $\mathrm{Al}$ em lugar do $\mathrm{Si}$, o que refina os grãos e melhora a tenacidade e a resistência ao impacto. Os aços com adição de alumínio não devem ser empregados para temperaturas acima de $380^{\circ} \mathrm{C}$, por que resistem menos à fluência e o alumínio inicia a grafitização. Para temperatura abaixo de $0^{\circ} \mathrm{C}$, deve ser feita a normalização para qualquer espessura. Para temperaturas acima de $0^{\circ} \mathrm{C}$, basta fazer normalização para espessuras superiores a $12 \mathrm{~mm}$. Embora sejam específicos para baixas temperaturas, são os preferidos para vasos de pressão e outros equipamentos importantes, para trabalho em toda faixa de temperatura aceitável para o aço-carbono.

Os aços de qualidade estrutural são destinados á construção de estruturas metálicas em geral. Podem ser empregados para suportes e peças internas ou externas, não sujeitas à pressão, e para tanques de armazenagem e outros vasos sem pressão, bem como alguns vasos e tubulações de baixa responsabilidade. $\mathrm{O}$ uso desses aços é proibido para partes de pressurizadas contendo fluídos tóxicos e também para tubulações de vapor de processo. Este tipo de aço não possui composição química completamente definida e, por esta razão, podem ter quantidade de carbono relativamente alta, ficando difíceis de soldar. Motivo pelo qual não devem ser empregados em nenhum caso para temperaturas inferiores a $0^{\circ} \mathrm{C}$. O limite de temperatura elevada para esses aços é de $340^{\circ} \mathrm{C}$, não recomendando o emprego para temperaturas superiores a $200^{\circ} \mathrm{C}$.

\section{II.2.5.2 AÇOS LIGA}

Aço que possui qualquer quantidade de outros elementos, além dos que entram normalmente na composição química dos aços-carbono, ou os aços que contenham os mesmos elementos do aço-carbono em proporções mais altas, como é o caso dos açosliga com manganês. Conforme a percentagem total de elementos de liga presentes, distinguem-se três classes:

- Aços de baixa liga - até 5\% de elementos de liga;

- Aços de média liga - de $5 \%$ a $10 \%$ de elementos de liga;

- Aços de alta liga - mais de $10 \%$ de elementos de liga. 
Aline R. V. Nunes, et al. / ITEGAM-JETIA Vol.02, Nº7, pp.04-16. Setembro, 2016.

A aplicação desses aços é necessária nos seguintes casos: altas ou baixas temperaturas, alta corrosão, necessidade de não contaminação, segurança ou alta resistência.

\section{II.2.5.3 AÇOS INOXIDÁVEIS}

- São aços de alta liga, contendo 12 a $26 \%$ de Cr, até $22 \%$ de $\mathrm{Ni}$ e freqüentemente, pequenas quantidades de outros elementos de liga.

- Não enferrujam, mesmo pela exposição prolongada a uma atmosfera normal.

- Empregados para os mesmos casos dos aços liga.

- Mais caros.

- Apresentam corrosão por pites e sob tensão em meios halogêneos.

\section{II.2.5.3.1 AÇOS INOXIDÁVEIS AUSTENÍTICOS}

São todos da série "300". São aços que possuem grande resistência aos hidrocarbonetos em temperaturas elevadas, mesmo na presença de compostos sulfurosos (ataque pelo $\mathrm{H}_{2} \mathrm{~S}$ ), sendo que para $300^{\circ} \mathrm{C}$ a corrosão é insignificante. Resistem muito bem ao ataque pelo hidrogênio, mesmo em altas temperaturas e pressões. Possuem muitos elementos de liga e nunca se rompem de maneira frágil sob tensão em várias temperaturas.

Esses aços apresentam estrutura com $\mathrm{FeY}$ em qualquer temperatura, não tendo, assim temperatura de transformação alfagama, e por isso, não são temperáveis em qualquer que seja o tratamento térmico efetuado. São materiais de solda fácil.

\section{II.2.5.3.2 AÇOS INOXIDÁVEIS FERRÍTICOS}

Possui resistência a corrosão menor do que os aços austeníticos. Apresenta soldabilidade muito difícil, devido ao crescimento exagerado do grão, o que resulta em fragilização na zona termicamente afetada pela solda. Este efeito é mais grave para aços com teor de $\mathrm{Cr}$ superior a $17 \%$.

$\mathrm{Na}$ composição química desses aços o teor de cromo normalmente é superior a $14 \%$, sendo que o tipo 446 com $27 \%$. Os aços ferríticos não possuem temperatura de transformação alfagama, por isso, não temperam, qualquer que seja o tratamento térmico, podendo endurecer quando submetidos a trabalhos de deformação a frio.

\section{II.2.5.3.3 AÇOS INOXIDÁVEIS MARTENSÍTICOS}

A maioria dos aços martensíticos apresenta um teor de cromo muito elevado em sua composição química, e, como consequiência, a solda desses aços é bastante difícil, podendo ocorrer um fenômeno de fissuração a frio pelo hidrogênio. Quando a quantidade de carbono for superior a $0,2 \%$ deve-se evitar soldas. Em temperaturas inferiores a $15^{\circ} \mathrm{C}$, estão sujeitos a fratura frágil. Todo material deve ser revenido e temperado.

Os aços martensíticos tal como os aços-carbono são capazes de temperar, podendo alcançar elevados valores de dureza e limite de resistência (até cerca de $190 \mathrm{~kg} / \mathrm{mm}^{2}$ ).

\section{II.2.5.4 METAIS NÃO-FERROSOS}

- Apresentam pouco ou nenhum ferro em sua composição.

- Apresentam melhor resistência a corrosão e preço superior aos aços-carbono.

- São empregados em alguns serviços especiais (serviços corrosivos e serviços criogênicos).

- Temperaturas muito elevadas;

- Serviços onde não é permitido contaminação do fluido contido.

\section{II.3 PRINCIPAIS NORMAS PARA VASOS DE PRESSÃO:}

- Estados Unidos - ASME Boiler and Pressure Vessel Code.

- Seção II - Materiais

- Define tensões admissíveis para os materiais utilizados em vasos de pressão.

- Utiliza como base os materiais definidos pela American Society for Testing and Materials (ASTM).

- Seção VIII - Vasos de Pressão

- Divisão 1 - Regras de projeto padrão

- Divisão 2 - Regras de projeto alternativo

- Divisão 3 - Regras de projeto alternativo para vasos de altas pressões.

- Inglaterra - British Standards Institution BS-5500

- Alemanha - A. D. Merkblatt

- França-Código SNCTTI

Segundo a norma N-253 da Petrobras, o projeto de todos os vasos de pressão deve ser feito rigorosamente de acordo com a edição citada nos documentos de projeto da Seção VIII, Divisão 1 (Pressure Vessels) do "Boiler and Pressure Vessels Code" da ASME. Contudo, há possibilidade de utilização de outras normas e as principais normas usadas no projeto são:

- N-253 - Projeto de Vaso de Pressão

- N-268 - Fabricação de Vaso de Pressão

- N-269 - Montagem de Vaso de Pressão

- N-550 - Projeto de Isolamento Térmico a Alta Temperatura

- N-1756 - Projeto de Proteção Contrafogo em Instalação Terrestre

- N-2012 - Bocal de Vaso de Pressão

- N-2013 - Suporte Para Vaso de Pressão Horizontal

- N-2014 - Suporte Para Vaso de Pressão Vertical

\section{II.3.1 DANOS POR CORROSÃO EM VASOS DE PRESSÃO}

Os principais mecanismos de deterioração dos vasos de pressão das unidades de hidrotratamento são decorrentes dos produtos gerados através da hidrogenação $\left(\mathrm{H}_{2} \mathrm{~S}, \mathrm{HCl}, \mathrm{NH}_{3}\right)$, presença de hidrogênio, severidade do processo (temperatura e pressão elevadas), ciclos térmicos sofridos, e do ataque eletroquímico em paradas, são extremamente críticos. Ocorrendo com maior intensidade nos sistemas de efluente do reator. Esses mecanismos levam a um progressivo dano em serviço, requerendo modificações nos procedimentos de inspeção e de operação e, em casos extremos, na perda do equipamento [4]. 
Aline R. V. Nunes, et al. / ITEGAM-JETIA Vol.02, Nº 07, pp.04-16. Setembro, 2016.

Alguns produtos e substâncias que operam nos vasos de pressão provocam tipos diferentes de corrosão, sendo a mais frequente a chamada "corrosão sob tensão".

$\mathrm{Na}$ corrosão sob tensão, tem-se a deterioração de materiais devido à ação combinada de tensões residuais ou aplicadas e meios corrosivos. Há uma ação sinérgica da tensão e do meio corrosivo, ocasionando a fratura em um tempo mais curto do que a soma das ações isoladas de tensão e corrosão. As tensões residuais que causam corrosão sob tensão são geralmente provenientes de operações de soldagem e deformações a frio, e as tensões aplicadas são decorrentes de condições operacionais como, por exemplo, pressurização de equipamentos [12].

Característica importante da corrosão sob tensão é que não se observa praticamente perda de massa do material. $O$ material permanece com bom aspecto até que ocorre a fratura. $\mathrm{O}$ tempo necessário para ocorrer corrosão sob tensão de um material metálico depende da tensão, da concentração ou natureza do meio corrosivo, da temperatura, da estrutura e da composição do material [12].

Os serviços com corrosão sob tensão mais comuns que atuam nos vasos de pressão, são: serviço com $\mathrm{H} 2 \mathrm{~S}$, serviço com soda cáustica e serviço com hidrogênio, que serão descritos a seguir.

\section{II.3.2 SERVIÇO COM H2S}

O ácido sulfídrico, em presença de umidade, provoca nos aços carbono corrosão sob tensão por sulfetos, conhecida como SSC (sulfide stress cracking), nas regiões de alta dureza dos equipamentos, normalmente soldas e zonas termicamente afetadas. $\mathrm{O}$ enquadramento dos equipamentos neste tipo de serviço pode ser obtido da norma da NACE (National Association of Corrosion Engineers) Standard MR-01-75, "Sulfide Stress Cracking Resistent Metallic Material for Oil Field Equipment", através de curvas em função da pressão parcial e da concentração (em ppm) de H2S, além da pressão total do sistema. Esta mesma norma estabelece uma série de requisitos para diferentes materiais, de forma a permitir seu uso nestas condições de serviço. Para os aços carbono e aços liga a dureza máxima deve ser de 200 Brinell (HB), após tratamento térmico, com medição conforme API-942. Também são requeridos [13].:

- Tratamento térmico de alívio de tensões;

- Radiografia total;

- Exame ultra-som nas chapas;

- Materiais com resistência inferior a $490 \mathrm{MPa}$;

- Dureza máxima para parafusos 235 Brinell (HB);

- Para alguns níveis de serviço é exigido controle de carbono equivalente e restrições na composição química:

- Para chapas:

- $\mathrm{S}=$ variando entre $0,008 \% \max$ a $0,002 \%$ $\max$;

- $\quad \mathrm{P}=$ variando de $0,020 \% \max$ a $0,010 \% \max$

- SA-515/516-60: $\mathrm{CE} \leq 0,41 \%$

- $\mathrm{SA}-515 / 516-70: \mathrm{CE} \leq 0,45 \%$

- Para tubos SA-106 e forjados SA-105:
- $\mathrm{CE} \leq 0,45 \%$;

- $\mathrm{C}=0,30 \% \max$.

O sulfeto de hidrogênio quando dissolvido em água é um ácido fraco e, portanto, corrosivo pelo fato dele ser uma fonte de íons hidrogênio. $\mathrm{Na}$ ausência de íons tamponantes a água em equilíbrio com 1 atm de $\mathrm{H}_{2} \mathrm{~S}$ possui um $\mathrm{pH}$ de mais ou menos 4 . Porém sob condições de formação em alta pressão esse $\mathrm{pH}$ pode atingir 3. O sulfeto de hidrogênio pode ter outras funções na indústria de óleo e gás. Ele atua como catalisador para promover a absorção pelo aço do hidrogênio atômico formado pela redução catódica de íons hidrogênio, o que é importante para aumentar a corrosão sob tensão na presença de sulfetos em aços de alta resistência com limites de escoamento maiores do que $690 \mathrm{MPa}$ ou $100 \mathrm{Ksi}$.

\section{II.3.3 SERVIÇO COM SODA CÁUSTICA}

Dependendo da concentração e da temperatura de $\mathrm{NaOH}$ poderá ocorrer corrosão sob tensão, conhecida com "fragilização cáustica", que exige tratamento térmico de alívio de tensões nas soldas e partes conformadas de equipamentos fabricados em aço carbono ou, a utilização de aços inoxidáveis ou ligas de níquel [13].

A figura 4, baseada na NACE - Corrosion Data Survey Metal Section, mostra três diferentes regiões para emprego de materiais:

- Região I: permitido o emprego de aço carbono, sem tratamento térmico;

- Região II: permitido o emprego de aço carbono, com tratamento térmico;

- Região III: não permitido emprego de aço carbono: devese adotar aço inoxidável austenítico para temperaturas até $100{ }^{\circ} \mathrm{C}$ e ligas de níquel (Monel) para temperaturas até $150{ }^{\circ} \mathrm{C}$

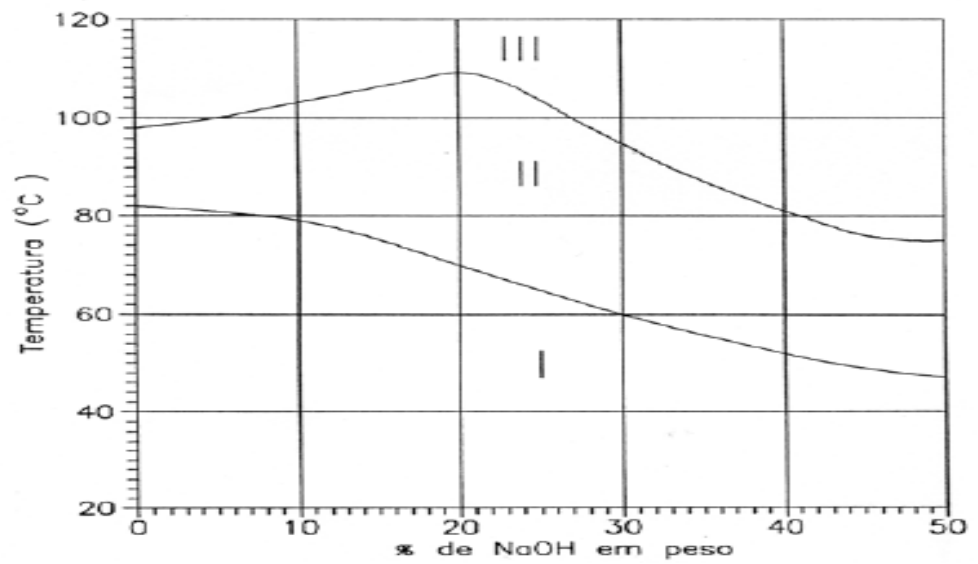

Figura 4 - Limites de utilização de materiais para serviço com soda cáustica.

Fonte: NACE, (2012).

\section{II.3.4 SERVIÇO COM HIDROGÊNIO}

Em equipamentos de refinarias de petróleo que processam hidrogênio ou fluidos contendo hidrogênio, deve-se verificar a possibilidade do ataque pelo hidrogênio. $\mathrm{O}$ ataque dos metais pelo hidrogênio, sob pressão e temperatura elevadas, 
raramente resulta na formação de películas sobre a superfície, e mesmo se houver formação de hidretos estes são estáveis [12].

A fragilização pelo hidrogênio está associada à difusão do hidrogênio atômico para o interior do metal, podendo ficar dissolvidos intersticialmente como hidrogênio atômico e ou precipitado na forma de hidrogênio molecular $(\mathrm{H} 2)$ em regiões de defeitos cristalinos onde a energia de interação com hidrogênio é maior do que entre o hidrogênio e os espaços intersticial da rede cristalina (ex: interface entre matriz e inclusões, contorno de grão, discordâncias). É basicamente uma reação de descarbonetação e pode ocorrer tanto na superfície quanto internamente no material, em que o hidrogênio reage com o carbono dos carbonetos existentes no aço para formar metano [4].

O hidrogênio provoca fissura induzida pelo hidrogênio, nos aços, conhecida como HIC (hydrogen induced cracking). A norma API-941- "Steels for Hydrogen Service at Elevated Temperatures and Pressures in Petroleum Refineries and Petrochemical Plants", do American Petroleum Institute (API), estabelece condições seguras para utilização de aços carbono e aços liga com este tipo de serviço. Os aços inoxidáveis austeníticos apresentam boas condições de utilização, independentemente dos parâmetros acima [13].

$\mathrm{O}$ ataque dos aços pelo hidrogênio pode ser evitado, ou minimizado, operando-se em temperaturas e pressões parciais de hidrogênio e composição de ligas evidenciadas nas curvas de Nelson preparadas para o API (American Petroleum Institute). Essas curvas devem ser usadas somente para prever condições que podem causar descarbonetação e fissuração nos aços [12].

\section{II.3.4.1. REQUISITOS BÁSICOS PARA SERVIÇO COM HIDROGÊNIO}

- Produto (condição de ocorrência): com presença de hidrogênio em pressão parcial acima de $4,5 \mathrm{kgf} / \mathrm{cm}^{2}$ (abs);

- Contaminantes: H2S e umidade;

- Meio: moderado a agressivo;

- Corrosão e falha: generalizada com taxas de 0,15 a 0,30 $\mathrm{mm} / \mathrm{ano}$, empolamentos localizados e fissuração devidos à penetração do hidrogênio atômico;

- Mecanismo de deterioração:

- Baixas temperaturas: risco de empolamento causado pela migração de $\mathrm{H}$ livre no fluido, para o interior da microestrutura do material: regiões de alta tensão, descontinuidades, segregações inclusões não metálicas ou contorno dos grãos. Ocorrem reações com os carbetos, gerando metano que fica aprisionado, levando simultaneamente à fragilização do material (pela perda de carbetos), às fissuras e trincas.

- Altas temperaturas: ataque pelo $\mathrm{H} 2\left(>250^{\circ} \mathrm{C}\right)$, se difundindo entre os grãos de de perlita, reagindo com a cementita, causando descarbonetação com a fragilização e trincamento intergranular. Empolamento localizado do material pela pressão do gás metano (H2 + carbonetos) formado nos contornos dos grãos e em dupla laminação das chapas.
- Material comumente usado: aço carbono acalmado ao Si e normalizados, com máximo de $0,005 \%$ e máximo de carbono equivalente $0,40 \%$. Adição de $\mathrm{Ca}$ para esferoidização de inclusões e aços ligas selecionados a partir das curvas de Nelson;

- END: radiografia total, partículas magnéticas antes e após o tratamento térmico e ultra-som total nas chapas e forjados (ainda na usina) e após a fabricação, nas soldas e ZTA's;

- Alívio de tensões: sempre necessário, com controle de dureza nas soldas e das zonas termicamente afetadas (ZTA) em no máximo 200HB (após tratamento térmico), e temperaturas de no mínimo $620^{\circ} \mathrm{C}$ para aços carbono;

- Normas aplicáveis: N-253 e N-1704 / API 941:

○ Somente são permitidos materiais aprovados no teste de suscetibilidade à fragilização ao $\mathrm{H} 2$, conforme NACE STD TM-02-84, com "CLR" máximo de $15 \%$ e "b" máximo de $0,1 \mathrm{~mm}$.

De acordo com Carlos Galvão, incluem ainda os seguintes requisitos adicionais exigidos para os aços carbono, tais como:

- Todas as soldas dos componentes dos equipamentos sujeitos à pressão e em contato com o fluido devem ser de penetração total;

- Reforços integrais para bocais: não são admitidos reforços com chapas sobrepostas;

- Exame de ultra-som, conforme ASTM-A-578, para chapas com espessuras acima de $12,5 \mathrm{~mm}$;

- Carbono equivalente:

$\begin{array}{ll}\circ & \text { SA-515/516-60: } \mathrm{CE} \leq 0,41 \% \\ \circ & \text { SA-515/516-70: } \mathrm{CE} \leq 0,45 \% \\ \circ & \text { SA-105/SA-106: } \mathrm{CE} \leq 0,45 \%\end{array}$

- Adicionalmente à composição química das especificações, se aplicam as seguintes restrições:

- SA-515/SA-516: $\mathrm{S}=0,003 \%$ max.; $\mathrm{P}=0,020 \%$ $\max . ; \mathrm{Al}=0,055 \% \max ;$

- SA-105/SA-106: $C=0,30 \% \max ; S=0,45 \% \max$; $\mathrm{P}=0,025 \% \max$;

A dureza das soldas e ZTA's deve ser medida de acordo com os procedimentos da prática API-RP-942 "Controlling Weld Hardness of Carbon Steel Refinery Equipment to Prevent Environmental Craking”. Os requisitos de inspeção de fabricação e montagem devem ser conforme as normas N-268 e N-269. Seguir a Norma N-1704 -"Requisitos Adicionais Para Vaso de Pressão em Serviço com Hidrogênio".

\section{II.4. REVESTIMENTOS EM VASOS DE PRESSÃO}

\section{II.4.1. REVESTIMENTOS INTERNOS}

Os metais empregados nos revestimentos anticorrosivos podem ter suas ações protetoras explicadas por diversos fatores. Esses metais usados nos revestimentos apresentam valores elevados de sobretensão ou sobrevoltagem, sendo por isso mais resistentes ao ataque ácido em meios não-aerados (caso do estanho, chumbo, zinco e cádmio). Da qualidade dos métodos 
Aline R. V. Nunes, et al. / ITEGAM-JETIA Vol.02, Nº 07, pp.04-16. Setembro, 2016.

empregados no revestimento e na limpeza das superfícies metálicas vai depender a boa aderência e a impermeabilidade da película, que são evidentemente condições essenciais para que haja proteção [12][14].

As técnicas mais frequentemente usadas para aplicação de revestimentos metálicos são: cladização, imersão a quente, aspersão térmica (metalização), eletrodeposição, cementação, deposição em fase gasosa e redução química [12][14].

O revestimento interno mais eficaz é a utilização de chapas cladeadas. São chapas de aço carbono revestidas por uma chapa fina de aço inoxidável. Os dois materiais são intimamente ligados, comportando-se como um único material. O aço carbono é dimensionado para resistir à pressão interna e o aço inox para suportar a agressividade do fluido.

Os Aços inoxidáveis austeníticos tipo 304L, 321 ou 347 são usados para garantir resistência à corrosão em altas temperaturas por compostos de enxofre, nas unidades de HDT, protegendo o substrato e por apresentar melhor resistência aos danos causados pelo hidrogênio em alta temperatura (metanização) [4].

A diferença da susceptibilidade ao ataque corrosivo de diferentes materiais, em meios contendo enxofre, pode ser observada na curva de McConomy Modificada (Figura 5), na qual se nota que os aços inoxidáveis da série 300 (austeníticos) apresentam uma maior resistência.

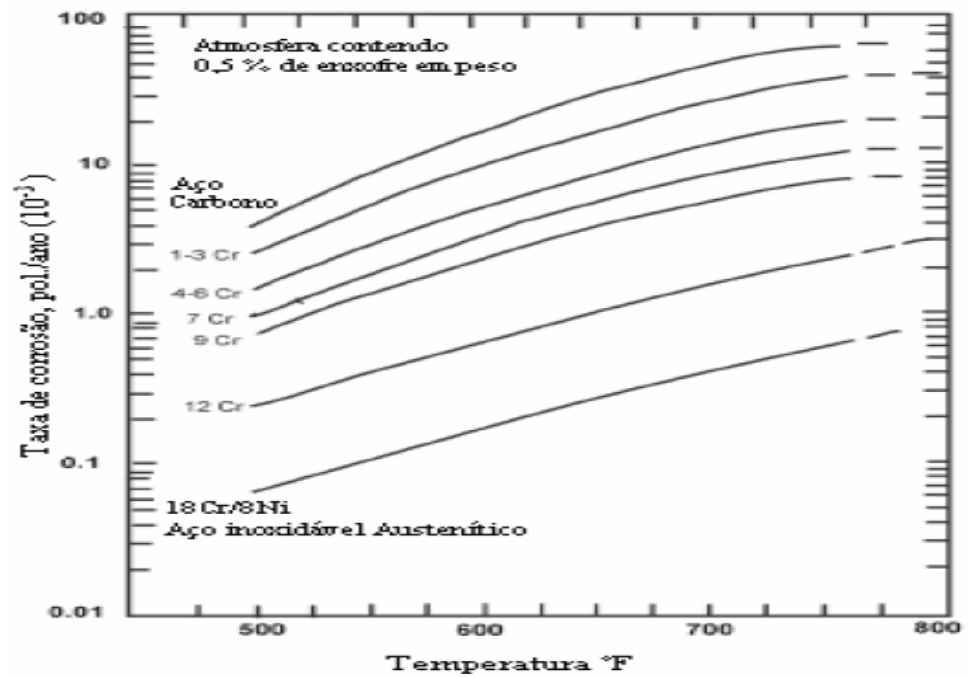

Figura 5- Curva de taxa de corrosão por compostos de enxofre $(0,5 \%$ em peso) - McConomy Modificada.

Fonte: [4].

Ainda é possível encontrar vasos em que o revestimento interno é não metálico. Este revestimento pode ser aplicado como pintura, sendo o revestimento mais comum a borracha clorada ou ainda, revestimento por resina reforçada com fibra de vidro. Um exemplo de aplicação deste último tipo de revestimento são os vasos de filtro de leito de sal. Estes vasos são utilizados no processo de fabricação do óleo diesel para remover a água existente no combustível. O diesel passa por um leito de sal grosso para que a água seja absorvida. Para suportar a agressividade deste meio o aço carbono precisa de um revestimento, e tem-se optado por revestir estes vasos, com resina reforçada com fibra de vidro.

\section{II.4.2 REVESTIMENTOS EXTERNOS}

Normalmente os vasos de pressão não têm nenhum revestimento externo. Apenas são pintados externamente. Entretanto é comum encontrar vasos com isolamento térmico, aplicado para conservação de calor ou proteção pessoal.

\section{COMO ESCOLHER CORRETAMENTE OS MATERIAIS PARA OS VASOS DE PRESSÃO}

De forma a exemplificar os métodos empregados para uma correta análise e seleção de materiais, tomaremos como exemplo um vaso de pressão com as seguintes condições de processo e serviço.

$\mathrm{Na}$ prática, o fabricante do equipamento envia documentos com as informações necessárias para a seleção e especificação do vaso de pressão. De posse dessas informações, será então analisado se o material especificado pelo fabricante para a construção do equipamento atende integralmente as exigências mínimas das normas de construção e das normas Petrobras. Segue abaixo as informações mínimas do processo para a seleção e especificação de materiais:

- A projetista de processo deve informar:

○ Composição química de cada corrente líquida, gasosa;

- Concentração dos contaminantes presentes:

- Pressão e temperatura normais de operação e de emergência que serão utilizados para a seleção do serviços dos equipamentos e sistemas de tubulação.

- No mínimo os seguintes dados, que afetam diretamente a seleção dos serviços, materiais de construção e requisitos de fabricação e montagem devem ser informados:

○ Pressão parcial de $\mathrm{H}_{2}$ e $\mathrm{H}_{2} \mathrm{~S}$ (caso esteja presente);

- ppm molar da fase gasosa e ppm em peso da fase líquida de Benzeno, $\mathrm{H}_{2} \mathrm{~S}, \mathrm{H}_{2}, \mathrm{NH}_{3}, \mathrm{NH}_{4} \mathrm{SH}, \mathrm{CO}_{2}$, $\mathrm{CO}, \mathrm{Cl}-, \mathrm{H}_{2} \mathrm{O}, \mathrm{NaOH}, \mathrm{O}_{2}$;

$\circ \mathrm{pH}$ da corrente fluida;

○ \% peso de Enxofre e mercaptans.

Essas informações devem ser apresentadas em forma de tabela e constar do fluxograma de processo. O objetivo desta seção é fornecer os requisitos mínimos para a escolha mais adequada do material a ser empregado em um vaso de pressão com serviço especial de hidrogênio.

Pela grande utilização dos códigos ASME, no Brasil, todas as especificações de materiais, aqui apresentadas, serão feitas com base nas especificações ASME Section II, Part A Materials - Ferrous Materials, ASME Section II, Part B Materials - Nonferrous Materials e ASME Section II, Part D Materials - Properties. Os materiais destas especificações são iguais ou muito similares aos materiais ASTM (American Society for Testing and Materials) que podem ser utilizados desde que sejam exatamente iguais aos materiais ASME, ou quando houver 
alguma diferença, o fabricante deve requalificá-los conforme as exigências do ASME.

O vaso de pressão, que pertence a Unidade de Hidrotratamento (HDT), exibe todas as características técnicas adotadas para a sua construção e essas informações são de extrema importância para a seleção de materiais. Uma vez conhecidas às condições de projeto e o fluído que circulará no equipamento passaremos a efetuar a seleção dos materiais para todas as partes do equipamento em contato com o fluído baseado na sua corrosividade.

- Condição de Projeto - $20 \mathrm{kgf} / \mathrm{cm}^{2}$ á $200^{\circ} \mathrm{C}$

- Diâmetro Interno - $1600 \mathrm{~mm}$

- Comprimento entre Tangentes - $5000 \mathrm{~mm}$
- Material base- aço-carbono SA-516-70 (Fornecedor)

- Fluido: Hidrogênio

A condição de projeto é a condição mais severa de temperatura e pressão simultâneas, as mesmas definem a condição de operação do vaso. A temperatura pode variar ao longo do comprimento do vaso e é considerada como sendo igual à temperatura do fluido, exceto quando há revestimento refratário. A pressão é medida no topo do equipamento e pode variar ao longo do vaso, em função da coluna hidrostática [5].

De posse do valor da pressão parcial informada pelo fornecedor $\left(20 \mathrm{kgf} / \mathrm{cm}^{2}\right)$ e da temperatura de projeto $\left(200^{\circ} \mathrm{C}\right)$, podemos utilizar as "curvas de Nelson", fazer a seleção da classe de serviço para esse vaso, conforme exibido na Figura 6.

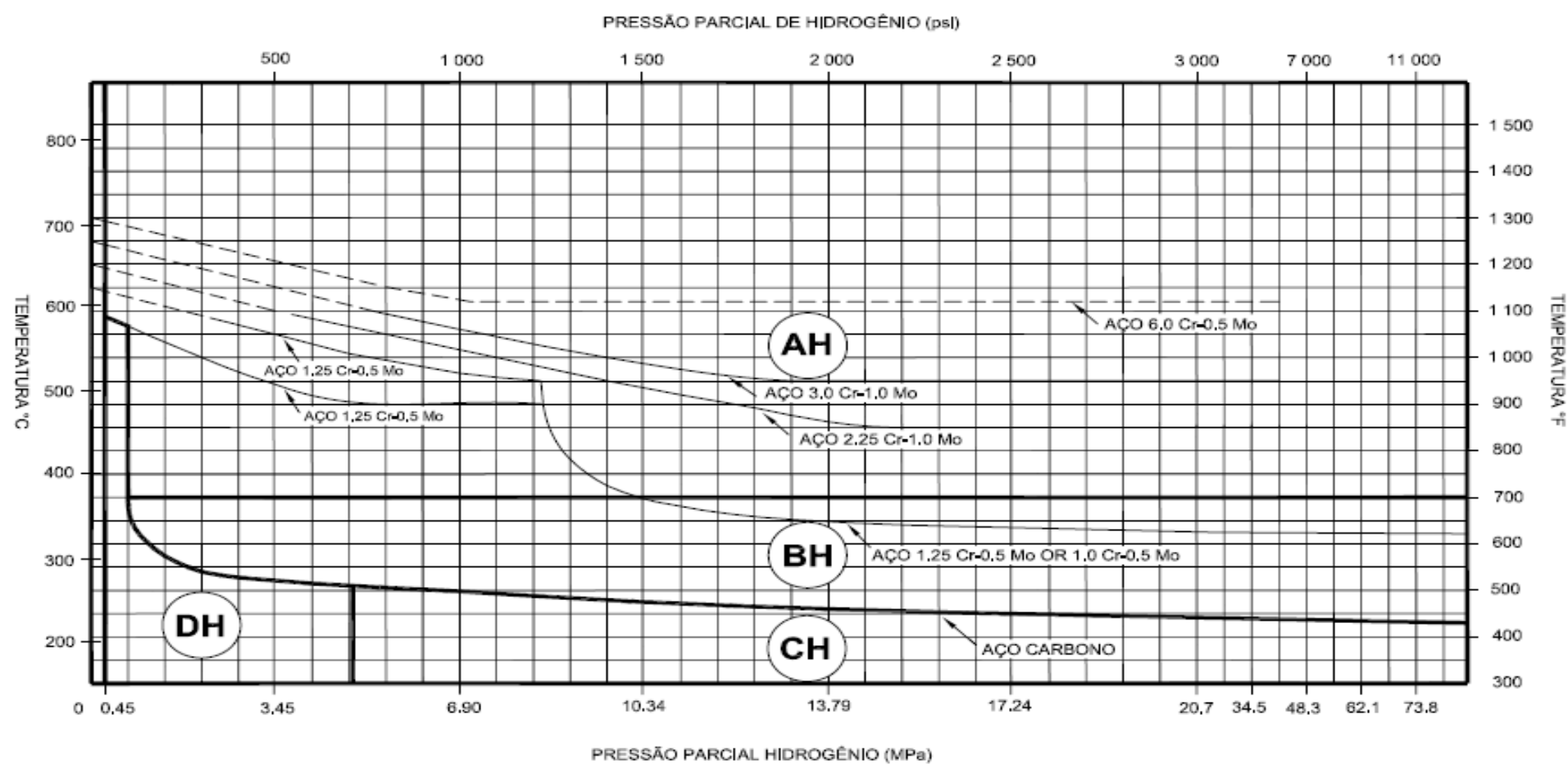

Figura 6 - Curvas de Nelson.

Fonte: [15].

Marcando na "curva de Nelson" o valor da pressão parcial (2 $\mathrm{MPa}$ ) do hidrogênio e o valor da temperatura de projeto $\left({ }^{\circ} \mathrm{C}\right)$, encontramos a classe $(\mathrm{DH})$ e o material base sugerido (Aço Carbono) para a aplicação. A Figura 7 exibe o tipo de material base sugerido de acordo com a classe do serviço.

\begin{tabular}{|c|c|c|}
\hline Classe & Severidade & Material Base Principal Sugerido \\
\hline $\mathrm{AH}$ & Máxima & $\begin{array}{l}\text { Aço alta e baixa liga Cr-Mo ou aço } \\
\text { inoxidável austenítico }\end{array}$ \\
\hline $\mathrm{BH}$ & & Aço baixa liga $\mathrm{Cr}-\mathrm{Mo}$ \\
\hline $\mathrm{CH}$ & 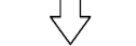 & Aço-carbono com exigências especiais \\
\hline $\mathrm{DH}$ & Mínima & $\begin{array}{l}\text { Aço-carbono com menor nível de } \\
\text { exigência }\end{array}$ \\
\hline
\end{tabular}

Figura 7 - Classes de equipamentos em serviço com hidrogênio.

Fonte: [15].
Após a seleção do material base do vaso, alguns requisitos devem ser seguidos de acordo com as normas N-253 e N-1704.

$\underline{\mathrm{N}-253}$

- $\quad$ Item 5.1 - Para os cascos, tampos e todas as outras partes do vaso submetidas à pressão exigem-se sempre que sejam especificados no projeto materiais qualificados. Como regra geral só são admitidos materiais qualificados reconhecidos pelo código ASME BPVC: 2010 Section II Parts D e Section VIII, admitindo-se materiais ASTM, detalhando-se os seus desvios para aprovação pela PETROBRAS.

- $\quad$ Item 5.4 - Os aços para as partes pressurizadas devem apresentar teor de carbono não superior a $0,30 \%$, sendo 
Aline R. V. Nunes, et al. / ITEGAM-JETIA Vol.02, No 07, pp.04-16. Setembro, 2016.

que para as chapas dos cascos e tampos exige-se que o teor de carbono, não seja superior a $0,26 \%$. Aços com teor de carbono superior aos limites acima podem ser empregados somente nos seguintes casos:

- Partes não soldadas, tais como: flanges cegos e tampos de bocas de visita;

- Chapas com espessura superior a $50 \mathrm{~mm}$.

N-1704

- Item 7.1 - Para qualquer vaso em serviço com hidrogênio, exige-se que todas as partes pressurizadas tenham como qualidade mínima de material os aços-carbonos totalmente acalmados.

- Item 7.4 - Devem ser do mesmo material que o casco, ou de material com composição e resistência ao hidrogênio equivalente, as seguintes partes: chapas de reforço de selas e chapas de reforço em geral. Devem ser previstos furos para respiro dos espaços sob essas chapas.

- Item 10.1 - Chapas para a Classe DH - As chapas devem ser de aço-carbono, fornecidas como totalmente
- acalmadas, preferencialmente das especificações SA 515/516 com os seguintes requisitos adicionais:

- Análise química de produto;

- Carbono equivalente: SA 515/516 Gr. $60 \mathrm{CE}=$ $0,41 \%$ (máx.) e SA 515/516 Gr. $70 \mathrm{CE}=0,45$ $\%$ (máx.).

O material base do vaso em questão informado pelo fornecedor (SA-516-70) atende ao requisito do item 10.1 da N1704, devendo o fornecedor informar se o carbono equivalente também atende a esse critério.

A partir do material base selecionada, pode-se especificar os materiais das demais partes do vaso de pressão. A Figura 8 mostra os critérios básicos para especificação de materiais para as diversas partes dos vasos de pressão. Esses critérios devem ser obedecidos, exceto quando for especificado de outra forma para um determinado vaso. As classes das partes dos vasos citados na primeira coluna da Tabela 3 são descritos abaixo [N-253].

\begin{tabular}{|c|c|c|c|c|}
\hline \multirow{2}{*}{\multicolumn{2}{|c|}{$\begin{array}{c}\text { Classe da parte } \\
\text { do vaso } \\
\text { considerada }\end{array}$}} & \multicolumn{3}{|c|}{ Material básico do vaso } \\
\hline & & Aço-carbono & $\begin{array}{l}\text { Aço-carbono para } \\
\text { baixas temperaturas }\end{array}$ & $\begin{array}{c}\text { Aços-liga, aços } \\
\text { inoxidáveis e metais } \\
\text { näo ferrosos }\end{array}$ \\
\hline & I & $\begin{array}{l}\text { Mesmo material do } \\
\text { casco. }\end{array}$ & $\begin{array}{l}\text { Mesmo material do } \\
\text { casco. }\end{array}$ & $\begin{array}{l}\text { Mesmo material do } \\
\text { casco. }\end{array}$ \\
\hline & II & $\begin{array}{l}\text { Mesmo material do } \\
\text { casco. }\end{array}$ & $\begin{array}{l}\text { Mesmo material do } \\
\text { casco. }\end{array}$ & $\begin{array}{c}\text { Material com o mesmo } \\
\text { "P-Number" do material } \\
\text { do casco. }\end{array}$ \\
\hline & III & $\begin{array}{c}\text { Aço-carbono de } \\
\text { qualidade estrutural. }\end{array}$ & $\begin{array}{c}\text { Aço-carbono para baixas } \\
\text { temperaturas. }\end{array}$ & $\begin{array}{l}\text { Material com o mesmo } \\
\text { "P-Number" do material } \\
\text { do casco (ver Nota). }\end{array}$ \\
\hline & IV & $\begin{array}{c}\text { Materiais especificados } \\
\text { em cada caso. }\end{array}$ & $\begin{array}{l}\text { Materiais especificados } \\
\text { em cada caso. }\end{array}$ & $\begin{array}{l}\text { Materiais especificados } \\
\text { em cada caso. }\end{array}$ \\
\hline & V & $\begin{array}{l}\text { Aço-carbono de } \\
\text { qualidade estrutural. }\end{array}$ & $\begin{array}{l}\text { Aço-carbono de } \\
\text { qualidade estrutural. }\end{array}$ & $\begin{array}{l}\text { Aço-carbono de } \\
\text { qualidade estrutural. }\end{array}$ \\
\hline & VI & $\begin{array}{l}\text { Aço-carbono de } \\
\text { qualidade estrutural. }\end{array}$ & $\begin{array}{l}\text { Aço-carbono de } \\
\text { qualidade estrutural. }\end{array}$ & $\begin{array}{c}\text { Material com o mesmo } \\
\text { "P-Number" do material } \\
\text { do casco. }\end{array}$ \\
\hline \multicolumn{5}{|c|}{$\begin{array}{l}\text { Deve ser empregado o mesmo material do casco, quando for exigido por motivo de } \\
\text { resistência à corrosão. }\end{array}$} \\
\hline
\end{tabular}

Figura 8 - Critérios para Especificação dos Materiais dos Componentes de Vasos.

Fonte: [11].

Alguns requisitos para a especificação de materiais para algumas das diversas partes dos vasos de pressão devem ser seguidos de acordo com as normas N-253 e N-1704.

\section{$\underline{\mathrm{N}-253}$}

- $\quad$ Item 8.5.1 - Para todos os flanges externos dos vasos, os parafusos devem ser tipo estojo, totalmente rosqueados, com rosca série UNC para diâmetros até 1 " e série $8 \mathrm{~N}$ para diâmetros maiores com 2 porcas hexagonais, série pesada, conforme normas ANSI B 1.1 e B 18.2, com classe de ajuste $2 \mathrm{~A}$ para o estojo e $2 \mathrm{~B}$ para as porcas. Exceto quando especificado em contrário, a seleção de materiais para estojos e porcas deve obedecer ao seguinte critério de acordo com a temperatura de projeto do vaso:

o Temperaturas entre $15{ }^{\circ} \mathrm{C}$ e $480{ }^{\circ} \mathrm{C}$ : estojos de aço-liga ASTM A 193 Gr. B7, porcas de aço liga e ASTM A 194 classe $2 \mathrm{H}$;

- $\quad$ Item 8.5.2.3 - Nos flanges com face para junta tipo anel (junta de anel oval de acordo com a norma ANSI B 16.20), o material do anel não deve formar par galvânico com o flange e sua dureza deve ser 30 "Brinell" inferior à dureza da face do flange. Para os materiais abaixo indicados, a dureza máxima deve ser:

o Aço-carbono: 90 "Brinell";

o Aço-liga 1 \% a 5 \% Cr: 130 "Brinell"; 
Aline R. V. Nunes, et al. / ITEGAM-JETIA Vol.02, Nº 07, pp.04-16. Setembro, 2016.

o Aço inoxidável 304, 316, 347 e 321: 130 "Brinell"; o Aço inoxidável 304L e 316L: 110 "Brinell".

- para a Classe DH - Devem estar de acordo com as especificações do código ASME Section II - SA 105, SA 106, SA 234 e SA 266, com os requisitos complementares:

○ $\mathrm{C}=0,30 \%$ máx.

○ $\quad \mathrm{CE}=0,45 \%$ máx

- Item 10.2.2 - A dureza medida dos tubos e acessórios de tubulação não deve ultrapassar $225 \mathrm{HV}$. A dureza medida dos forjados não deve ultrapassar $190 \mathrm{HV}$.

Em seguida a Figura 9, mostra uma especificação de materiais de um determinado vaso de pressão com material base em aço carbono com serviço de hidrogênio. Evidentemente que deve encarar essas recomendações como um guia prático, sujeito às adaptações e modificações que julgadas necessárias, em função das informações mais precisas do produto manuseado e das conveniências que o mercado impõe.

N-1704 [15].

- Item 7.3 - As saias de vasos verticais devem ter um trecho com um comprimento mínimo de $1000 \mathrm{~mm}$ do mesmo material que o casco e tampo inferior ou de material com composição e resistência ao hidrogênio equivalente.

- Item 10.2.1 - Forjados, Tubos e Acessórios de Tubulação

\begin{tabular}{|c|c|c|c|c|}
\hline \multicolumn{3}{|c|}{ Componente } & \multirow{2}{*}{\begin{tabular}{|l|} 
Material \\
SA -516 Gr. 60 \\
\end{tabular}} & \multirow[t]{2}{*}{ Comentários } \\
\hline 1 & Casco & & & \\
\hline \multirow{3}{*}{2} & \multirow{3}{*}{ Tampos } & Superior & SA - 516 Gr. 60 & \\
\hline & & Inferior & SA. -516 Gr. 60 & \\
\hline & & Intermediánio & SA -516 Gr. 60 & \\
\hline \multirow{3}{*}{3} & \multirow{3}{*}{ Bocais } & Flange & SA -105 & \\
\hline & & Pescoço & SA - 106 Gr. B & \\
\hline & & Luva & - & \\
\hline \multirow{2}{*}{4} & Boca de visita & Flange & SA -105 & Chapa SA - 516 Gr. 60 ou 70 \\
\hline & Inspeção e desgaste & Pescoço & SA -515 Gr. 60 & \\
\hline 5 & \multicolumn{2}{|l|}{ Bota (casco e tampo) } & SA. -515 Gr. 60 & \\
\hline 6 & \multicolumn{2}{|l|}{ Flanges de corpo } & SA - 105 & Chapa SA - 516 Gr. 60 ou 70 \\
\hline 7 & \multicolumn{2}{|l|}{ Reforços em aberturas } & SA- -515 Gr. 60 & Forjado SA - 105 \\
\hline \multirow{2}{*}{8} & \multirow{2}{*}{ Tubos } & Pressurizados & SA - 106 Gr. B & \\
\hline & & Não pressurizados & SA - 53 Gr. B & \\
\hline 9 & \multicolumn{2}{|c|}{ Acessórios de tubulação } & SA - 234 Gr. WPB & \\
\hline \multirow{2}{*}{10} & \multirow{2}{*}{ Acessónios soldados } & Internos & SA. -515 Gr. 60 & \\
\hline & & Externos & SA -516 Gr. 60 & \\
\hline \multirow{2}{*}{11} & \multirow{2}{*}{ Internos } & Fixos & SA -515 Gr. 60 & \\
\hline & & Removiveis & SA. - 240 Gr. 304 & \\
\hline 12 & \multicolumn{2}{|l|}{ Bandejas e Pratos } & SA - 240 Gr. 304 & \\
\hline 13 & \multicolumn{2}{|l|}{ Demister } & AISI - 304 & \\
\hline \multirow{2}{*}{14} & \multirow{2}{*}{ Distribuidores } & De tubos & SA - 312 Gr. 304 & \\
\hline & & De chapas & SA - 204 Gr. 304 & \\
\hline 15 & \multicolumn{2}{|l|}{ Sprays } & AISI - 304 & \\
\hline 16 & \multicolumn{2}{|l|}{ Recheios } & Pelo Processo & \\
\hline 17 & \multicolumn{2}{|l|}{ Grades } & SA - 204 Gr. 304 & \\
\hline 18 & \multicolumn{2}{|c|}{ Válvulas e Borbulhadores } & A.ISI - 304 & \\
\hline \multirow{3}{*}{19} & Parafusos & Internos & Inox TP -304 & \\
\hline & e estojos & & SA - 193 Gr. B7 & \\
\hline & e porcas & Externos & SA - 194 Gr. H2 & \\
\hline 20 & \multicolumn{2}{|c|}{ Grampos de Atracação } & Inox TP -304 & \\
\hline 21 & Telas e Arames & & AISI - 304 & \\
\hline $2 ?$ & אברטיטי & Internas & $100 \%$ Amianto & \\
\hline 22 & Juntas & Externas & Inox Aust + Amianto & Espiralada \\
\hline 23 & Suportes de vasos & & SA -516 Gr. 60 & \\
\hline 24 & Anéis de Reforço & & SA -516 Gr. 60 & \\
\hline 25 & Chumbadores & & SA - 307 Gr. B & \\
\hline
\end{tabular}

Figura 9 - Especificação dos Materiais dos Componentes de Vasos com serviço de $\mathrm{H}_{2}$. Fonte: Autores, (2016).

Recomendações:

- O material SA - 516 Gr. 70 com $0,26 \%$ de C máximo

- Os materiais SA - 515, SA - 505, SA - 506 e SA - 234 devem atender a:

○ Os seguintes teores máximos: $0,005 \% \mathrm{~S} ; 0,020 \% \mathrm{P}$; $1,0 \% \mathrm{Mn} ; 0,40 \%$ Ni e $0,40 \% \mathrm{Cu}$

○ Carbono equivalente (CE): 0,40\% Máx.

- Materiais conforme teste Nace STD TM - 04 - Co4 (HIC)

\section{ISOLAMENTO TÉRMICO}

A norma N-550 [16] da Petrobras seleciona o tipo de material e a espessura do isolante térmico de acordo com os seguintes critérios:

- Conservação de energia calorífica;

- Proteção ou conforto pessoal.

A determinação da espessura do(s) isolante(s) tem por objetivo evitar danos ou desconforto pessoal. 
Aline R. V. Nunes, et al. / ITEGAM-JETIA Vol.02, № 07, pp.04-16. Setembro, 2016.

- O isolamento deve garantir na superfície externa uma temperatura abaixo de $60^{\circ} \mathrm{C}$.

- $\mathrm{O}$ isolamento deve ser feito em equipamentos ou tubulações localizados a uma altura inferior a 2 metros de qualquer piso, ou a uma distância lateral inferior a 1 metro de escadas ou plataformas destinadas ao trânsito pessoal.

\section{CONCLUSÕES}

Com o objetivo de descrever os procedimentos para uma correta análise e seleção de materiais a serem utilizados em vasos de pressão, que atendesse com segurança as condições de serviço dentro de uma refinaria, baseados no código ASME, nas normas PETROBRAS e ASTM, foi elaborado um método que reuniu de uma forma sistemática as informações necessárias para se realizar a tarefa de especificar os materiais dos vasos de pressão de uma uma unidade de HDT, identificando cada possível serviço, selecionando o material base apropriado, estabelecendo os requisitos de fabricação necessários, especificando o material padronizado mais conveniente para cada peça e componente do equipamento.

\section{REFERÊNCIAS BIBLIOGRÁFICAS}

[1]. JÚNIOR, G. Processamento Primário do Petróleo: Noções de Processo de Refino. Tecnologia em Petróleo e Gás - UNIT.

$<$ http://www.tecnicodepetroleo.ufpr.br/apostilas/engenheiro_do_ petroleo/processamento_primario.pdf> Acesso em julho de 2013.

[2]. GONZAGA, A.C., ARAÚJO, K. D. Danos em serviço em unidades de processo: um estudo de caso. Monografia apresentada ao Programa de Pós-Graduação em Engenharia de Tubulação da PUC Rio.Rio de Janeiro, 2010.

[3]. DIAS, Flaviana RF; FERREIRA, Vitor F.; CUNHA, Anna Claudia. Uma visão geral dos diferentes tipos de catálise em síntese orgânica. Revista Virtual de Química, v. 4, n. 6, p. 840-871, 2012.

[4]. LEAL, M. F. Simulação de Diferentes Tratamentos Térmicos na Aceitação do Aço 2,25Cr-1Mo Adotado em Equipamentos para Hidrotratamento de Derivados de Petróleo. Dissertação de Mestrado - Departamento de Ciência dos Materiais e Metalurgia, Pontifícia da Universidade Católica do Rio de Janeiro, Rio de Janeiro, 2008. 77p.

[5]. Silva TELleS, P. C. Vasos de Pressão. Editora LTC, $2^{\circ}$ ed., Rio de Janeiro, 2005.

[6]. SZKLO, A. S. Fundamentos de Refino de petróleo. Editora: Interciência, Pag. 208, 2005.

[7]. MIRRE, Reinaldo Coelho et al. Análise de redes de distribuição de hidrogênio em refinarias através da técnica de integração de processos. 2008.
[8]. RNEST - Refinaria do Nordeste. Relatório de impacto ambiental, 2006. Disponivel em: <http://www.petrobras.com.br/pt/meio-ambiente-esociedade/preservando-meio-ambiente/ licenciamentoambiental/> Acesso em Julho de 2013.

[9]. TOMAZINI, Guilherme Abreu. Diretrizes básicas para projetos de vasos de pressão segundo a ASME Trabalho. 2015.

[10]. MARTINS, Filipe José Soares. Análise da possibilidade de crescimento subcrítico de descontinuidades durante a realização de testes hidrostáticos em vasos de pressão e seus possíveis efeitos. 2009.

[11]. PETROBRAS N-253 - Projeto de Vaso de Pressão.

[12]. GENTIL, V. Corrosão. 4a ed. Rio de Janeiro: LTC Editora, p. 341, 2003.

[13]. FAlCÃO, C. Projeto Mecânico Vasos de Pressão e Trocadores de Calor de Casco e Tubos. Texto registrado sob o número 65030 no Escritório de Direitos Autorais da Fundação Biblioteca Nacional do Ministério da Cultura, 2002.

[14]. MADALENA, Francisco Carlos Albuquerque et al. estudo de propriedades mecânicas e microestruturais do aço inoxidável superaustenítico aisi 904l utilizado como revestimento interno de vasos de pressão fabricados em aço carbono astm-a-516 grau 70. 2013.

[15]. PETROBRAS N-1704 - Requisitos Adicionais Para Vaso de Pressão em Serviço com Hidrogênio.

[16]. PETROBRAS N-550 - Projeto de Isolamento Térmico a Alta Temperatura. 